ISSN: 2162-3104 Print/ ISSN: 2166-3750 Online Volume 6, Issue 1 (2016), pp. 14-34

(C) Journal of International Students http://jistudents.org/

\title{
International and American Students' Perceptions of Informal English Conversations
}

\author{
Eun Jeong (Esther) Lee \\ Claflin University (USA)
}

\begin{abstract}
This study investigated international and American students' perceptions of structured but informal English conversations with each other. American and international students perceived the effects of these conversations differently. While the international students claimed increased linguistic and cultural competence, the Americans identified cultural exchange as the main benefit: they shared their own cultures and experiences and learned more about their conversation partners' home countries. Both sets of participants associated these benefits with a non-threatening and non-judgmental atmosphere and emphasized the importance of comfort and friendship. Understanding these expectations and assessments can help ESL program administrators design effective informal conversation programs, and help identify opportunities for ESL improvement outside of formal coursework.
\end{abstract}

Keywords: Informal English conversation, cultural exchange, ESL learning environments, second language (L2)

In the past decade, American universities have become the globally premier providers of tertiary education, resulting in substantial increases among international student populations. According to the Institute of International Education's “Open Doors 2012: Report on International Educational Exchange" (2012), the number of non-immigrant international students enrolled in accredited U.S. higher education institutions on temporary visas increased $6 \%$ in the 2011-12 school year, to a record high of 764,495-4\% of total U.S. college and university enrollment. New international student enrollment also increased $6.5 \%$ in 2012, to 228,467 students. For the first time since 2000-01, undergraduate international students $(309,342)$ 
outnumbered graduate international students (300,430) in 2011-12. Nurturing an internationally diverse student body can generate considerable educational, cultural, and economic benefits for U.S. universities and their students. For instance, connecting and communicating with international students can not only increase American students' awareness of cultural diversity, but also foster their communication skills, preparing them to interact effectively and sensitively in a diverse global market.

To achieve such benefits, however, universities must actively encourage international student retention. Whether international students persist in their studies at U.S. universities is closely related to how they navigate a series of difficult and complex sociocultural, psychological, and linguistic adjustments. The present study's findings suggest that structured informal English conversations, in which American students are paired with international students, can positively address these challenges in ways that formal classroom lessons sometimes miss. Indeed, Lee and Song (2009) points out that being able to understand and converse in English during everyday interactions is a high priority for many L2 learners, often because such conversations combine English practice with improved cultural competence. However, the present study also demonstrates that international and American students approach structured informal conversations with different goals and expectations: though both groups valued the intercultural friendships they developed, international students most valued the chance to improve their oral English proficiency, while American students emphasized how they learned about global cultures and helped their international conversation partners to cope with American academic cultures.

Although these goals are not mutually exclusive, understanding both sets of priorities is valuable from an administrative perspective. ESL program administrators, along with ESL faculty, commonly encourage international students to make friends with their American classmates, and to practice their English in non-academic contexts. University-run English conversation programs offer a convenient framework for these processes, especially for American students interested in TESOL, but they can also frustrate students who seek different outcomes from their respective conversation partners. An international student, for instance, may expect detailed attention to grammar and syntax while her American partner may be more interested in wide-ranging conversations about customs and culture. Acknowledging and discussing these differences can greatly improve course planning and training, and help both groups of students balance their expectations while still maintaining a positive, comfortable environment for practicing English. 


\section{LITERATURE REVIEW}

\section{Informal Interactions with Native Speakers of English}

Informal interactions with native speakers have been recommended as a means to improve communicative skills, in both academic and nonacademic English learning environments (Johnston, 1996-7; Lee \& Song, 2009; Lussier, Turer, \& Desharnais, 1993; Martin, 1980; Yager, 1998; Zhang, 2005). Informal learning environments have been defined as "natural setting[s]...where learning takes place in real life situations and meaning is derived partly from context" (d'Anglejan, 1978; Krashen, 1976; Krashen \& Seliger, 1975, as cited in Spada, 1985, p. 51). For adult learners, these informal setting may include work and social settings that focus on meaning, in contrast to formal classrooms "where the target language is being taught to a group of second or foreign language learners" and where "the focus of learning is on the language itself” (Bahrani \& Sim, 2012, p. 143). According to Rogers (2004), while formal language learning is "structured, purposeful, and school-based," informal language learning is unstructured and may lack a specific pedagogical purpose. Yet informal learning is "the most extensive and most important part of all the learning that all of us do every day of our lives” (as cited in Bahrani \& Sim, 2012, p. 142). Therefore, informal interactions with native speakers could be designated as natural contact occurring in a realistic environment (Lee \& Song, 2009).

Many studies on informal interactions between native English speakers and ESL/EFL speakers have shown that these interactions improve ESL and EFL students' conversational skills, oral proficiency, and self-confidence in their oral English (Johnston, 1996-7; Lee \& Song, 2009; Lussier, Turer, \& Desharnais, 1993; Martin, 1980; Yager, 1998; Zhang, 2005). Similarly, Martin (1980), Johnson (1983), Johnston (1996-7), and Yager (1998) show how important interaction with native speakers is for all L2 language learners, regardless of the target language. Furthermore, by interacting with native speakers, international students studying in America have an opportunity to learn about American culture, American lifestyles, and colloquial English. In other words, students are exposed to a variety of second language inputs and outputs.

Because such interactions often feature modified input to improve comprehensibility (Long, 1981; Gass \& Mackey, 2007), and because they help form social relationships (Pica, 1987), they offer a range of potential benefits. These conversations do not simply serve as additional English practice sessions but as valuable social interactions. In particular, Long 
(1996) emphasizes how "negotiation for meaning, and especially negotiation work that triggers interactional adjustments by the native speaker (NS) or more competent interlocutor, facilitates acquisition because it connects input, internal learner capacities, particularly selective attention, and output in productive ways” (pp. 451-452). While these features are not necessarily unique to informal conversations, they often arise more naturally there than in classroom exercises or teacher-initiated corrective feedback.

To examine these effects more precisely, the present study follows a suggestion in Gareis, Merkin, and Goldman's (2011) study. They state that more studies are needed to examine both "which aspects of linguistic proficiency have the greatest bearing on friendship formation (including vocabulary, accent, register, and language pertinent for functions, such as texting or phoning)," and to evaluate the efficacy of international and American students' perceptions of their training needs (Gareis, Merkin, \& Goldman, 2011, p. 167). Understanding these perceptions better can not only help ESL instructors and administrators design more effective informal conversation tasks and programs but can also improve their insight into the different pedagogical opportunities that informal conversations offer. This study explores a single research question: What benefits do American students and international students perceive as resulting from informal English conversations, and what goals do they have for those conversations?

\section{RESEARCH METHOD}

\section{Participants}

The participants were 20 pairs of English conversation partners; each international student (ICP-International Conversation Partner) was paired with an American student (ACP-American Conversation Partner). All 40 students enrolled in the English Conversation Partners (ECP) Program at a large public university in the United States, during the Fall 2012 semester. These students spanned three age ranges: $18-22$ years $(\mathrm{n}=10$ international students; $\mathrm{n}=13$ American students), 23-26 years ( $\mathrm{n}=8$ international students; $n=4$ American students), and 27-30 years $(n=2$ international students; $\mathrm{n}=3$ American students). All of the 18-22 year olds were undergraduate students, all the 23-26 year olds were Masters students, and all the 27-30 year olds were $\mathrm{PhD}$ students. In terms of gender, the international group consisted of 13 female students and 7 male students, while the American group had 14 females and 6 males. However, only one pair of male students volunteered for the follow-up interviews, so the interview group was $90 \%$ female. 
Table 1: Interviewed Participants' Background Information

\begin{tabular}{|c|c|c|c|c|c|}
\hline Name * & Age & Gender & $\begin{array}{l}\text { Home } \\
\text { Country }\end{array}$ & $\begin{array}{c}\text { Area of Study } \\
\text { (UG/MA/ PhD) }\end{array}$ & $\begin{array}{l}\text { Prior } \\
\text { English } \\
\text { (Years) }\end{array}$ \\
\hline 1a. A1 & 33 & Female & USA & Pharmacy, MD & 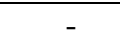 \\
\hline 1b. I1 & 25 & Female & Vietnam & Business, MBA & 7 \\
\hline 2a. A2 & 20 & Female & USA & Public Affairs & - \\
\hline 2b. I2 & 19 & Female & China & Business, UG & 9 \\
\hline За. А3 & 18 & Female & USA & Biology, UG & - \\
\hline 3b. I3 & 24 & Female & Singapur & Design, MA & 10 \\
\hline 4a. A4 & 23 & Female & USA & Communication, MA & - \\
\hline 4b. I4 & 19 & Female & Palestine & Economics, UG & 7 \\
\hline 5a. A5 & 19 & Female & USA & Art \& Science & - \\
\hline 5b. I5 & 21 & Female & China & Business, UG & 6 \\
\hline 6a. A6 & 20 & Female & USA & International Studies, UG & - \\
\hline 6b. I6 & 26 & Female & Korea & Economics, PhD & 7 \\
\hline 7a. A7 & 20 & Female & USA & International Studies, UG & - \\
\hline 7b. I7 & 20 & Female & Taiwan & Business, UG & 14 \\
\hline 8a. A8 & 20 & Female & USA & Dental Hygiene, UG & - \\
\hline 8b. I8 & 23 & Female & China & Administration, MA & 13 \\
\hline 9a. A9 & 27 & Male & USA & City \& Reg. Planning, MA & - \\
\hline 9b. I9 & 23 & Male & Korea & Political Science, UG & 6 \\
\hline 10a.A10 & 19 & Female & USA & Psychology UG & - \\
\hline 10b. I10 & 22 & Female & China & Engineering, PhD & 10 \\
\hline
\end{tabular}

* These are all pseudonyms. "A" indicates an American student, and "I" indicates an International student.

All the American students were from the Midwest, while the 20 international students were from a variety of countries: 10 were Chinese, 4 Korean, 1 Vietnamese, 1 Taiwanese, 1 Palestinian, 1 Indian, 1 Singaporean, and 1 was Japanese. Fifteen of the international students had just arrived at the university that semester, and the remaining 5 students had started the previous Fall. Similarly, 17 international students and 16 American students were new to the ECP program in Fall 2012. The remaining three international students had also participated in Spring 2012 while the American students had more experience: one had two semesters in the program, two had three semesters, and one had four semesters.

Ten pairs of conversation partners (20 students) participated in in-depth follow-up interviews. All the American interviewees were from the Midwest, and the international interviewees were from several different countries: 4 were Chinese, 2 Korean, 1 Taiwanese, 1 Vietnamese, 1 Singapore, and 1 was Palestinian. In terms of gender, all but one interviewed pair consisted of two female participants. Table 1 shows the backgrounds of the interviewed students; $\mathrm{a}$ and $\mathrm{b}$ indicate a conversation pair. 


\section{Setting}

The present study was conducted in the English Conversation Partner (ECP) program at a large public university in the United States. Though the university has run the ECP program since 2006, thus far no formal studies have evaluated its benefits or efficacy. Accordingly, this study plays a significant role in assessing the program. The program's host university ranks 10th nationally in international student enrollment (Open doors 2012 fast facts). According to the university's statistics for 2012, the total number of enrolled international students was around 6,000, and a high proportion of these students came from Asia: 2,757 from China, 609 from India, and 537 from South Korea. The ECP Program matches American students with international students who would like to learn more about American English and American culture via informal English conversations. American student volunteers likewise have the chance to share their linguistic and cultural knowledge, and to learn about another culture. Conversation partners meet on a weekly basis throughout the semester (a minimum of two hours a week), at a time of their choosing. During these meetings, both partners practice their English conversation skills, and both have the opportunity to share linguistic and cultural knowledge.

\section{Instruments}

The present study used a mixed research method that includes both quantitative and qualitative approaches. Adding the qualitative data helps shed light on the causal relationships at work in the study (Smith, 2003; Ragin, Nagel, \& White, 2004). The initial survey questionnaires included both quantitative and qualitative questions while in-depth follow-up interviews with a subset of the survey respondents enriched the qualitative data. The international student survey differed slightly from the American student survey, but both versions were used to gather data relevant to the research question. In the descriptions below, variant questions are identified by A or I, depending on whether they appear in the American or international survey.

Before moving on to the survey components in detail, it is important to note that their results were based on participants' self-reports, which they provided at the end of the semester. As such, they are subject to the participants' own biases, and may show overly optimistic views of the conversations, their effects on the ICPs English skills, and the intercultural friendships. The interviews may suffer from similar biases since students who had positive experiences may have been more likely to volunteer for follow-up interviews. However, since the goal of this study is to identify and characterize student goals and perceptions, and not to demonstrate a causal 
relationship between informal conversations and oral English improvement, these potential biases do not invalidate the data. In fact, they may improve the study's applicability for ESL program management since they help reveal the students' ideal goals and results, even if those results may be colored by some wishful thinking.

Each survey was divided into three parts. The first part for international students consisted of twelve questions that explored their backgrounds in learning English; its counterpart for the American students was comprised of seven questions about their general background. The second part of both surveys, consisting of nine questions, scrutinized the effectiveness of informal English conversations on improving international students' oral English proficiency (see Appendices A and B for both surveys). The international students evaluated the efficacy of these conversations on their own proficiency, while each American student likewise assessed his or her ICP. Specifically, Questions 1 and 2 sought to identify and account for the international student's most difficult language skill, while Questions I3 and I4 evaluated international students' past opportunities to practice oral English and communicate in English. Along similar lines, Questions A3 and A4 asked American students to describe their challenges and difficulties in communicating with their ICPs and suggest ways their respective conversation partners should develop their oral English. Questions 5 and 6 were identical in both surveys and garnered ratings of the international student's overall oral English proficiency before and after participating in the ECP program. The remaining three questions (Questions 7, 8, and 9) in this section examined various effects of the ECP conversations in greater detail.

First, Question 7 assessed how much the international student's English had improved in seven specific linguistic areas (Speaking, Pronunciation, Listening, Grammar, Vocabulary, Idiom Usage, and Colloquial English), using a seven-point Likert-type scale ranging from "Little" to "Much." Question 8 evaluated how much both conversation partners learned about each other's cultures, lifestyles, experiences, and different academic environments, using a six-point Likert-type scale ranging from "Strongly Disagree" to "Strongly Agree." Participants responded to a set of eight declarative statements. The last question (Question 9) included 12 items to rate, three measuring each of four affective variables (self-confidence, attitude, anxiety, and motivation). This question used a seven-point Likerttype scale ranging from "Little" to "Much." However, the researcher later opted to leave this data out of the analysis, to save space.

Finally, the third part of the survey examined the students' qualitative perceptions of the ECP program, through three open-ended questions. These 
questions were primarily focused on the roles and functions of the ECP program, the benefits of having an English conversation partner, and the potential necessity for both native and non-native English speakers to participate in an ECP program. Later, follow-up interviews with a subset of the survey respondents (see Procedures section, below) expanded on the students' responses, to supplement the quantitative survey data. The interviews emphasized the effectiveness of the ECP program and the pedagogical value of informal English conversations for both international and American students, with respect to their cultures, lifestyles, and different academic environments.

\section{Procedures}

The study design required forty student participants (20 international students and 20 American conversation volunteers). In order to get this number of participants, the researcher met with the director of the ECP program in the middle of October 2012 to get her permission to conduct this study. In the first week of November, the director forwarded a detailed description of the study, along with a consent form, to all students enrolled in the ECP program. The email clarified that students would participate as pairs. In the last week of November, the students who consented to participate received a link to an online survey. Then, at the end of the survey questionnaire, the students were asked if they were willing to participate in a face-to-face follow-up interview with the researcher.

Ten pairs (10 international students and their 10 American English conversation partners) agreed to the interviews, and each student was interviewed individually for an hour, two weeks after the questionnaire. The interviews probed in greater depth and detail the participants' goals in the ECP program, and their perceptions of the program's overall effectiveness. Member checks were used in order to corroborate face validity, and the recurring themes in the students' responses were coded and classified. The interviews were conducted in English, in a quiet and empty classroom. Each interview was recorded and immediately transcribed. To compare how international and American students viewed their conversations in terms of cultural exchange, the mean values of each item in Question 8 were used. This analysis included comparing each student's Question 8 responses to his or her partner's responses. In order to identify the relationship between the international students' conversation goals and common L2 difficulties, seven survey questions were analyzed: the three questions on the international students' backgrounds in learning English, and the four questions on which language skill those students found most difficult to develop since coming to the US. For the latter group of questions, the 
American students also evaluated their conversation partners' linguistic difficulties (see Appendices A and B).

\section{RESULTS}

Research Question: What benefits do American students and international students perceive as resulting from informal English conversations, and what goals do they have for those conversations?

\section{Quantitative Results}

Figure 1 and Table 2 show international and American students' experiences of informal English conversations by comparing the mean values on Question 8 in the second part of both surveys, in which respondents rated eight declarative statements. International students gave two statements a mean rating of above 5.0, indicating substantial agreement: "The ECP's relaxed atmosphere made me feel comfortable speaking in English," and "The friendly relationship with my American conversation partner helped me speak English more confidently and fluently." However, the ICPs assigned a mean value of only 4.80 to a comparable statement about cultural exchange (Item 2 in Table 2), and a mean value of only 4.55 to a comparable statement about learning about other cultures and lifestyles (Item 1 in Table 2). This result suggests that international students perceive that they benefit from the ECP program more in terms of oral English improvement than of learning about cultural aspects of American academic life.

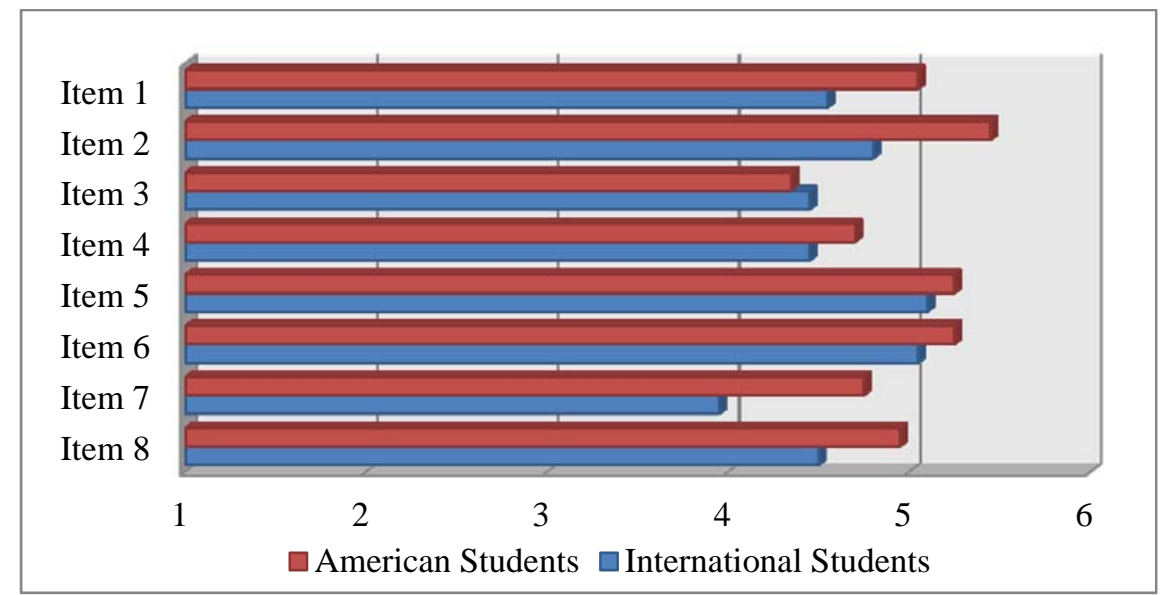

Figure 1. International and American Students' Experiences of Informal English Conversations 
On the other hand, the Americans emphasized cultural exchange and sharing personal experiences, giving the following statements a mean rating of greater than 5: "Our conversation's relaxed atmosphere made my nonnative conversation partner feel comfortable speaking in English," "My friendly relationship with my conversation partner helped him or her speak English more confidently and fluently," "I often share my own cultures and experiences with my English conversation partner," and "I’ve learned a lot about my conversation partner's culture and lifestyle."

\section{Table 2: International and American Students' Experiences of Informal English Conversations}

\begin{tabular}{|c|c|c|}
\hline Items & $\begin{array}{l}\text { International } \\
\text { Students } \\
\operatorname{Mean}(S D)\end{array}$ & $\begin{array}{l}\text { American } \\
\text { Students } \\
\text { Mean(SD) }\end{array}$ \\
\hline Item 1: Learning cultures and lifestyles & $4.550(.686)$ & $5.050(.605)$ \\
\hline Item 2: Sharing cultures and experiences & $4.800(.833)$ & $5.450(.686)$ \\
\hline $\begin{array}{l}\text { Item 3: Recognizing different ways of } \\
\text { speaking English }\end{array}$ & $4.450(.945)$ & $4.350(1.348)$ \\
\hline $\begin{array}{l}\text { Item 4: Understanding each other's different } \\
\text { schoolsystems and academic } \\
\text { environments }\end{array}$ & $4.450(.999)$ & $4.700(1.302)$ \\
\hline $\begin{array}{l}\text { Item 5: ECP's relaxed and comfortable } \\
\text { atmosphere }\end{array}$ & $5.100(.788)$ & $5.250(.639)$ \\
\hline $\begin{array}{l}\text { Item 6: Friendly relationship between the } \\
\text { conversation partners }\end{array}$ & $5.050(.826)$ & $5.250(.639)$ \\
\hline $\begin{array}{l}\text { Item 7: Providing oral corrections on ICP's } \\
\text { English mistakes and errors. }\end{array}$ & $3.950(.1 .605)$ & $4.750(1.251)$ \\
\hline $\begin{array}{l}\text { Item 8: Informal English conversation taught } \\
\text { ICP correct English }\end{array}$ & $4.500(1.192)$ & $4.950(.887)$ \\
\hline
\end{tabular}

\section{Qualitative Results}

Research Question 1 scrutinized the benefits, for both international and American students, of cultural exchange and informal English learning environments. The quantitative results demonstrate that both conversation partners agreed that "the ECP's relaxed atmosphere made international students feel comfortable speaking in English" and "the friendly relationship with both conversation partners helped international students speak English more confidently and fluently," giving both items a mean rating of above 5.0. These quantitative results raise the question of how and why informal English conversations in relaxed environments, coupled with friendly relationships with American students, significantly impacted the 
international students' spoken English. Accordingly, the follow-up interviews more precisely sought out how this phenomenon happened, and why it was important for both conversation partners to have these comfortable environments and friendly relationships. The following interview excerpts are from I1 (a Vietnamese international student) and her American conversation partner A1:

When I speak English in class or with some of my classmates, I always have fear: what if they cannot hear me, and what if they think they waste their time because of my deficient speaking skill. That's why I always try to polish my words, use the simplest word to avoid being misunderstood or mistaken, and in that situation I don't think I practice the difficult words to improve my oral English. But, in the ECP program, the intimate environment encourages me to talk about everything, use the words that I rarely use at school and learn from my mistakes. The relaxed atmosphere makes me feel less hesitant in speaking (I1's personal interview, Dec 14, 2012).

I don't want her to feel nervous about talking with me, about making mistakes or something. I know from my own experience, the reason a lot of students don't necessarily talk in class is because they don't want to be wrong or make a mistake. I want her to feel comfortable, and to ask questions, and to know that, you know, I'm here as a friend, and I'm not grading her or anything like that (A1's personal interview, Dec 13, 2012).

Since English is not the international students' native language, in general they have a high level of anxiety and a natural fear about speaking it. Therefore, creating a non-threatening and non-judgmental atmosphere for informal English conversations with American students played an important role in helping them to speak English freely and confidently, and also to lower their anxiety levels about making utterance errors or mistakes. In addition to a relaxed and comfortable atmosphere, participants also highlighted the advantages of a friendly relationship between conversation partners. This finding also supports Woodrow's (2006) statement that there is a need to form more relaxed L2 learning environments to lower students' second language anxiety, as well as to be more sensitive to whether students receive sufficient interaction opportunities to facilitate their oral development and diminish their timidity and shyness. Consequently, establishing relaxed atmospheres with less pressure and fear has a significant impact on fostering international students' willingness to communicate with American students, and doing so encourages them to practice their oral English. 
In short, more comfort in an environment with peers and friends allowed international students to speak English more freely, and generated less fear and anxiety about their errors and mistakes. Unlike in the classroom environments that include grades and nervousness, here close relationships with a friend helped both international and American students to share their feelings, ideas, and cultures. Specifically, this intimate relationship enabled international students' personal problems and questions to bubble to the surface so that they could get support and help from their American conversation partners. This finding buttresses Gareis, Merkin, and Goldman's (2011) argument that "increased friendship with host nationals means more opportunities to learn about host culture and language, better social integration, greater sojourn satisfaction, and more positive views of the host country" (p. 168). As a result, informal English conversations made it possible for both conversation partners to get into each other's comfort zone and communicate. Overall, informal English conversations with American students provided international students with a platform to improve their oral English and to establish friendships with Americans.

\section{DISCUSSION}

\section{Linguistic and Cultural Benefits of Informal Conversations}

Ten of the ICPs indicated that their limited vocabulary and knowledge of proper expressions served as one major source of their difficulty with speaking English. By the same token, several ACPs pointed out that their ICPs' speaking difficulty came from being unfamiliar with colloquialisms, including slang, idioms, and natural English expressions. In fact, nine ACPs identified their major challenge in communicating with their ICPs in English as having to explain American slang and colloquial terms. This difficulty supports Engkent's (1986) idea that “[t]eaching colloquial English is a decoding process, an explanation of the way the language works and what can be expected of it” (p. 233). One of the international interviewees compared her difficulty learning American idioms and colloquial speech English with facial recognition:

If you are very familiar with a person, maybe your parents, or your sisters, and you can recognize the picture, the photographs of this person very accurately, with few errors; even though the photograph is under different illumination or different poses, you can also recognize them very well. But if it is an unfamiliar person, even though people give you several photographs of him or her to train you [...] that's just temporary. Then after a while, even if you are just given other photographs of the same person, you may still 
not have high accuracy recognizing, in recognizing him or her. I think the same thing happens to the Americans (I10's personal interview, Dec 13, 2012).

In this metaphor, formal English is like the faces of family and friends, while American idioms and colloquial English are new to the ICPs, and they're strange because they don't behave the way formal English does. Therefore, it takes longer for L2 speakers to feel comfortable with them and to know when they're being used correctly. For this reason, 17 out of 20 ACPs suggested that their ICPs should develop their oral English by continuing to practice speaking English with native English speakers, preferably in a situation similar to the ECP program.

Indeed, despite the ICPs' environmental limitations and drawbacks, the ECP conversations did make it possible for them to practice speaking English, adjust to American students' fast speaking speed, and learn more about how to use proper vocabulary and expressions in real-life contexts. Because idioms and slang often rely on culturally inflected word meanings, even ICPs with high test scores on vocabulary may struggle to use the words they learn idiomatically. Although they recognized that they need to learn American idioms and colloquial speech expressions to communicate with Americans in real conversations, doing so could be puzzling if they learned only one standard definition for each word. This difficulty, according to the participants, also reflects cultural differences between the US and the ICPs' home countries. For instance, ACPs might deem a certain idiom appropriate based on contextual cues, but the international students might not think so because they are not very familiar with the idiom. Likewise, Americans might intend to use idioms in a humorous way, but the humor may be lost on - or even offend-international listeners. While formal ESL courses cover some idiomatic and colloquial speech, it's often more natural to encounter and process informal English in the contact of a conversation. Most conversations, though, leave little room for explanation or repetition, partly because most people do not expect to explain what seems like everyday speech. The ECP's structured approach, however, included room for metalinguistic explanations without disrupting the natural flow of conversation.

\section{English Improvement vs. Cultural Exchange}

One interesting quantitative result of RQ 1 was that international students perceived their oral English improvement as the main benefit from the ECP program (mean values: 5.10/6.00 and 5.05/6.00), whereas American students identified cultural exchange as the main benefit, both by sharing their own cultures and experiences with their ICPs (mean value: 
5.45/6.00), and by learning about their ICPs' cultures and lifestyles (mean value: 5.05/6.00). The following interview excerpts show what kinds of cultural knowledge and experiences the American students exchanged with their ICPs. The last excerpt emphasizes what elements of the ICP's cultures and lifestyles the American speaker learned through informal English conversations.

The first couple times we met, she was a lot quieter, so I did a lot of talking. I told her about, like, prom, and the high school experience of prom, and we talked a lot about the election, and I explained the whole weird Electoral College thing. Well, it helps them learn; one thing that I think I really helped my partner learn that is like different aspects of the culture, being a student, and even just like the [university] culture. I told her about the football games, and I don't know if she knew what football was. I don't remember, I might have had to explain that to her too, but I was telling her about the games. I took her to Chipotle one time, which was, like, college students' favorite place to eat. She didn't like it, but she tried it! And so, I just think that, like, she's having these American experiences, and it's helping her (A10's personal interview, Dec 11, 2012).

I see a lot of foreign students around campus, but I've never interacted with anyone from a foreign country before. And so it was really cool; she would tell me stuff like, figuring out her undergrad experience in China, and some different cultural things, like she told me about feng shui one time, and it was just really interesting. Because, I mean, you could read that stuff out of a book, but it just doesn't seem real until you actually talk to someone (A8's personal interview, Dec 14, 2012).

Overall, these informal conversations gave American students many opportunities to share about their own cultures and experiences, and likewise provided international students with opportunities to get involved in American cultures and their communities, if sometimes indirectly. Their conversation topics included campus sports, representative holidays and festivals, family relationships, different school systems, and even American elections. These cultural contexts effectively supplemented the ICPs ESL classes: learning about the targeted language cultures let them reaffirm and expand what they knew about the United States, and gave them more chances to talk about those things in English. As a result, informal English conversations with American students enriched the international students' 
contextual understanding of English, since language develops based on cultural conformities and cultural exchange. Even though the international students as a group rated cultural exchange as a relatively less important benefit (4.80/6.00, compared to the Americans' 5.45/6.00), one of the international students offered a useful reminder of the centrality of culture in language learning:

The major benefit of being in America is learning the real culture of America, not just learning English. Through my American conversation partner, I could learn American cultures, which made me a stronger English user, and I felt better in expressing myself to him. In informal English conversations, since the international students want to improve their English, I think it would be good for them to learn American cultural things beyond improving speaking skills (I9's personal interview, Dec 12, 2013).

Aside from this one example, however, none of the other ICPs discussed their ECP conversations in terms of cultural exchange: most were far more concerned with improving their oral English. This goal, of course, is very common among L2 learners. According to Swain (1993, 1995, 1998), output practice has a noticing/triggering function, which enables L2 learners to notice the gap between "what they want to say and what they can say, leading them to notice what they do not know, or know only partially" (Swain, 1995, pp. 125-6). Through output opportunities with ACPs in real conversations, not only has the ICPs' oral English improved, but they also noticed the contrasting ways of using English between what they learned in class and what they produce in conversation. Practice not only refers to "any activity designed to provide L2 learners with opportunities to produce output” (Muranoi, 2007, p. 52), but also has an important effect on L2 improvement in a more rapid and stable way (Ranta \& Lyster, 2007). In this respect, the ECP program offered a platform for ICPs to practice and produce their oral English in an informal way, within a series of comfortable and relaxed atmospheres.

One of the ICPs described her English education in terms of accumulation vs. application. Her words reveal more precisely how insufficient opportunity to practice speaking English in their home countries prevented the ICPs from communicating with American students, and how informal English conversation helped remedy this deficiency:

When I first came here, I started to speak in English. This was my first time to actually speak in English. But I felt that I was not 
really using what I'd learned so far in Korea. I was like accumulating all of my English speaking ability, but had no chance to actually practice it and speak. Right? And then when I started to speak with my conversation partner, I just realized that, yeah, I'm using what I've accumulated so far. I tried to use expressions that I've learned so far, to see how I can actually use this expression, and to see how other people are speaking, and how people are using those expressions. Then I can see how I can actually use this expression and what kind of things I should not say, and what kind of good expressions will fit into this specific situation (I6's personal interview, Dec 8, 2012)

Although this student, like many of her fellow ICPs, recognizes the practical applications of informal conversations, she still conceptualizes those conversations strictly in terms of linguistic improvement. Her partner's primary function in this schema seems to be a sounding board, offering English practice from a basically pedagogical perspective. This attitude arguably allows for some cultural exchange, insofar as all language reflects and refracts the speaker's culture, but, in this case, the student did not actively seek out cultural knowledge or cultural exchange.

\section{Scaffolding More Effective English Learning}

All of the interviewed students praised the ECP's positive effects on their linguistic and cultural education and recommended that all international students participate in informal conversations with American students to supplement their classroom English education. These conversations, they argued, help not only to improve the international students' oral English but also to help them adapt them to westernized academic environments and life in the US. Ideally, this process should start during a student's first semester in the US. At this point, having just arrived in the US, international students are eager to learn new things. Similarly, meeting with an ACP at this stage is very important and helpful for them to practice their oral English, to establish friendships, and to adjust to American academic environments and life in the US. Eventually, the international students will feel more comfortable and have more confidence to communicate with Americans while living in the US.

Many international students who come to the U.S. in order to complete their education have had few meaningful interactions with American students. Therefore, having more interactions with native speakers in an informal way provides them more enriching experiences of learning colloquial English. Doing so might also address international students' 
common complaint about a lack of close friendships with host nationals (Bochner, McLeod, \& Lin, 1977; Furnhan \& Alibhai, 1985; Kudo \& Simkin, 2003; Gareis, 2012; Ward \& Masgoret, 2004). It can also help them gain self-confidence in using their informal English to strike up conversations with Americans in a relaxed atmosphere and a friendly relationship. In accordance with Branden (2007), it is very important to create "a relatively safe learning environment in which L2 learners are offered rich opportunities for context-embedded practice and using the L2 in semi-real operating conditions, making sure that, at the same time, the learners' selfconfidence is boosted, anxiety levels are held down, and ample opportunities for practicing items of the target language and negotiating for meaning become available” (p.174). Therefore, learning informal English through the ECP program might constitute a rich scaffold for natural English communication outside of the classrooms: it can provide the basic infrastructure for international students to improve their oral English proficiency, have confidence in speaking English, increase cultural competence, and acclimate to American cultures.

The interview data demonstrate that in an informal setting, the ICPs were able to communicate and practice their English in a low-pressure but enjoyable and effective environment. These results confirm that structured informal conversation programs like the ECP are beneficial, but also that differing student expectations can present administrative challenges. To maximize productivity and effectiveness, program administrators need to manage mismatches between these expectations as by doing so they can ultimately improve both American and international students' experience. As shown in the present study, in this case, the international students wanted to improve their English proficiency whereas the American students wanted to experience cultural exchange. Students in other programs, of course, may have different priorities, and conscientious assessment-ideally both before and after the program—can help identify these goals.

To reduce the gaps between American and international expectations, American students should undergo detailed training before starting the program, perhaps in conjunction with formal coursework. Such training should cover how to communicate with international students, how to make international students feel comfortable enough to talk with American students, how to teach basic ESL, and how to correct international students' English errors in a sensitive and non-threatening manner. In addition, program administrators should suggest or assign conversation topics and specific activities in advance, to encourage both conversation partners to share information about and experience with each other's culture, lifestyles, foods, educational environments, communities, and societies. While informal conversations cannot and should not substitute for formal ESL 
coursework, these practices will enable American students to provide international students with practical and realistic assistance to enhance their oral English proficiency.

\section{LIMITATIONS AND FUTURE WORK}

The present findings were based on self-reports by the participants in the ECP program. This study should be replicated to include pre- and postsurveys, to more accurately and precisely trace both student expectations and the effects of informal English conversations. In order to obtain more significant statistical differences, future studies need to include more pairs of American students and international students, at both the survey and interview stages. More specifically, more research needs to be done on what formal vs. informal English is from both American and international students' perspectives, and why it is important for international students to learn both types of English in a balanced way.

Further research on this topic should also include more longitudinal case studies, to investigate how long-term conversation-based friendships with American students influence international students' oral English improvement. Specifically, future work should measure how informal conversations with American students might change the relationships between international student's formal and informal English. Overall, more detailed case studies could explore how international students' increased communicative adaptability and English language proficiency might affect how they make friends with American students, their academic accomplishments and satisfaction levels with their studies, and their acculturation in the US. These new directions could enrich or complicate this study's findings about the benefits of informal English conversations between international and American students, and the place of those conversations in L2 English education.

\section{REFERENCES}

Bahrani, T., \& Sim, T. S. (2012). Informal language learning setting: technology or social interaction? TOJET: The Turkish Online Journal of Educational Technology, 11(2), 142-149.

Bochner, S., McLeod, B. M., \& Lin, A. (1977). Friendship patterns of overseas students: A functional model. International Journal of Psychology, 12, 277-294.

Branden, K. V. D. (2007). Second language education: Practice in perfect learning conditions? In R. M. DeKeyser (ed.), Practice in a second language (pp. 161-179). Cambridge, NY: CUP. 
Cresswell, J. W. (1995) Research design: Qualitative and quantitative approaches. Thousand Oaks, CA: Sage.

d'Anglejan, A. (1978). Language Learning in and out of classroom. In J. Richards (ed.), Understanding second and foreign language learning (pp. 218-236). Rowley, MA: Newbury House.

Engkent, L. P. (1986). Real people don't talk like books: Teaching colloquial English. TESL Canada Journal/Revue TESL Du Canada, $1,225-234$.

Furnham, A., \& Alibhai, N. (1985). The friendship networks of foreign students: A replication and extension of the functional model. International Journal of Psychology, 20, 709-722.

Gareis, E., Merkin, R., \& Goldman, J. (2011). Intercultural friendship: Linking communication variables and friendship success. Journal of Intercultural Communication Research, 40(2), 153-171.

Gareis, E. (2012). Intercultural friendship: Effects of home and host region. Journal of International and Intercultural Communication, 5(4), 309-328.

Gass, S. M., \& Mackey, A. (2007). Input, interaction, and output in second language acquisition. In B. VanPatten and J. Williams (eds.), Theories in second language acquisition: An introduction (pp. 175199). Mahwah, NJ: Lawrence Erlbaum.

Institute of International Education (2012). Open Doors Report 2012: Report on international educational exchange. Retrieved November, 12, 2012 from http://www.iie.org/Research-and-Publications/OpenDoors

Johnson, D. M. (1983). Natural language learning by design: A classroom experiment in social interaction and second language acquisition. TESOL Quarterly, 17(1), 55-68.

Johnston, G. (1996-7). Mixing ESL students with native-speaker basic education students. Pennsylvania Action Research Network [PAARN] Monograph.

Kudo, K., \& Simkin, K. A. (2003). Intercultural friendship formation: The case of Japanese students at an Australian university. Journal of Intercultural Studies, 24(2), 91-114.

Krashen, S. D. (1976). Formal and informal linguistic environments in language acquisition and language learning. TESOL Quarterly, 10, 157-168.

Krashen, S. D., \& Seliger, H. (1975). The essential contributions of formal instruction in adult second language learning. TESOL Quarterly, 9, 173-183.

Lee, E. \& Song, H. (2009). A study of L2 learners' perceived efficacy of one-on-one English conversation with native speakers. Foreign 
Languages Education, 16(1), 29-52.

Long, M. H. (1981). Input, interaction, and second language acquisition. Annals of the New York Academy of Sciences, 379, 259-278.

Long, M. H. (1996). The role of linguistic environment in second language acquisition. In W. Ritchie and T. K. Bhatia (eds.), Handbook of second language acquisition (pp. 413-468). San Diego: Academic Press.

Lussier, D., Turer, C. E., \& Desharnais, S. (1993). Measuring second language (L2) proficiency in high school level exchange students. The Canadian Modern Language Review 49, 526-549.

Martin, G. (1980). English language acquisition: The effects of living with an American family. TESOL Quarterly, 14, 388-390.

Muranoi, H. (2007). Output practice in the L2 classroom. In R. M. DeKeyser (ed.), Practice in a second language (pp. 51-84). Cambridge, NY: Cambridge University Press.

Pica, T. (1987). Interlanguage adjustment as outcome of NS-NNS negotiated interaction. Language Learning, 38(1), 45-73.

Ragin, C. C., Nagel, J., \& White, P. (2004). Workshop on scientific foundations of qualitative research. Washington, DC: National Science Foundation.

Ranta, L., \& Lyster, R. (2007). A cognitive approach to improving immersion students' oral language abilities: The awareness-practicefeedback sequence. In R. M. DeKeyser (ed.), Practice in a second language (pp. 141-160). Cambridge, NY: Cambridge University Press.

Rogers, A. (2004). Looking again at non-formal and informal educationtowards a new paradigm, the encyclopedia of informal education, www.infed.org/biblio/non_formal_paradigm.htm. Last updated: June 04, 2004.

Rubin, D. L. (1992). Nonlanguage factors affecting undergraduates' judgment of non-native English-speaking teaching assistants. Research in Higher Education, 33, 511-31.

Smith, R. C. (2003). Complementary articulation: Matching qualitative data and quantitative methods. In. C. C. Ragin, J. Nagel \& P. White (eds.), Workshop on scientific foundations of qualitative research (pp. 101104). Washington, DC: National Science Foundation.

Spada, N. (1985). Effects of informal contact on classroom learners L2 proficiency: A review of five studies. TESL Canada Journal, 2(1), 51-62.

Swain, M. (1985). Communicative competence; some roles of comprehensive input and output in its development. In S. Gass \& C. Madden (eds.), Input in second language acquisition (pp. 235-53). 
Cambridge, MA: Newbury House.

Swain, M. (1993). The output hypothesis: Just speaking and writing aren’t enough. The Canadian Modern Language Review, 50, 158-164.

Swain, M. (1995). Three functions of output in second language learning. In G. Cook, \& B. Seidlhoffer (eds.), Principles \& practice in applied linguistics: Studies in honor of H. G. Widdowson (pp. 125-44). Oxford: Oxford University Press.

Ward, C., \& Masgoret, A. M. (2004). The experiences of international students in New Zealand: Report on the results of the national survey. New Zealand: International Policy and Development Unit, Ministry of Education.

Woodrow, L. (2006) Anxiety and Speaking English as a Second Language. RELC Journal, 37(3), 308-328.

Yager, K. (1998). Learning Spanish in Mexico: The effect of informal contact and student attitudes on language gain. Hispania, 81(4), 898913.

Zhang, L. (2005). Development of oral communication skills by Chinese students in Canada: Case studies. Doctoral dissertation, The University of Western Ontario.

EUN JEONG (ESTHER) LEE, Ph.D., is the Director of the Intensive English Language Program and an Assistant Professor of English and Foreign Languages at Claflin University. Her specific research interests include corrective feedback, the affective elements of L2 pedagogy, emotion and learning, informal English conversations, ESL learning patterns, curriculum development, and ESL program management. Email: eulee@claflin.edu. 